\title{
The Application of Japanese Electronic Media in Japanese Learning
}

\author{
Xiuxia Cui ${ }^{1,2}$, Hiroyuki Honda ${ }^{2 *}$, and Yukari Nagai ${ }^{2}$ \\ ${ }^{1}$ School of Foreign Language, Dalian Polytechnic University, Dalian, China \\ ${ }^{2}$ Knowledge Science Department, Japan Advanced Institute of Science and Technology, Nomi, Japan
}

\begin{abstract}
With the development of internet technology, language learning had become different from the past. A variety of electronic media are used as a means of learning Japanese. This paper makes a questionnaire survey of Japanese majors in a university in China, and clarifies the students' application of Japanese electronic media, and analyzes the problems faced by students. This paper makes suggestions on how to use Japanese electronic media correctly to help to learn Japanese. Using learners' love of Japanese electronic media, stimulating their motivation to learn Japanese, making full use of online resources, encouraging learners to use time outside the classroom to learn scientifically and effectively is our research topic.
\end{abstract}

\section{Introduction}

With the development of internet technology, our life changed differently, with a smartphone people can watch videos and read stories anytime, anywhere. We spend far more time online than face-to-face communication with real people. Language learning is no exception, it had become different from before too. Various websites, WeChat, Youtube, and other video websites have become online resources for language learning. In China, many people because they like Japanese animation, games, movies, and so on and began to learn Japanese. Watching Japanese animation, television programs, TV dramas, movies, and other electronic media, is becoming a new learning way.

However what about the students in the Japanese major? What is the impact of Japanese majors on Japanese learning by watching Japanese media? Therefore a specific investigation had been done at Dalian Polytechnic University in China, limiting students in Japanese major for their use of Japanese electronic media.

\section{Literature review}

Tokumaru (2018) [1] had done qualitative research on selflearner who started learning Japanese through watching Japanese animation. He realized use Japanese electronic media to listen to Japanese was the most important for learning. Nishiharas(2016) [2] researched an evaluation method of the degree of difficulty of spoken lines of comics of Japanese language learners. They pointed the learners can train themselves to make conversations in Japanese by reading/listening to the spoken lines, however, there may be spoken lines that are hard to understand for the beginners because they do not have enough knowledge of Japanese. N.Fukui and S.Kawaguchi[3] said, with the development of communication technology, learners also have the opportunity to use Japanese outside the classroom. Active use of these new resources for better use of technology for out-of-class activities be asked to go. So, finding a good way how to use the Japanese electronic media to help Japanese learning, is required.

\section{Investigation}

\subsection{Purpose of investigation}

We gave the investigation for three purposes: (1) to reveal the influence of Japanese electronic media on Japanese majors; (2)to identify the use of Japanese electronic media by Japanese majors; (3) to find an effective using method of the Japanese electronic media.

\subsection{Subjects of investigation}

A total of 135 Japanese majors at Dalian Polytechnic University had been the subjects. The details are shown in Table.1. Subjects of investigation (persons).

Table.1. Subjects of investigation(persons)

\begin{tabular}{|l|c|c|c|}
\hline & Male & Female & Total \\
\hline Grade1 & 1 & 27 & 28 \\
\hline Grade2 & 5 & 25 & 30 \\
\hline Grade3 & 5 & 34 & 39 \\
\hline Grade4 & 3 & 35 & 38 \\
\hline Total & 14 & 117 & 135 \\
\hline
\end{tabular}

\footnotetext{
* Corresponding author: honda-h@jaist.ac.jp
} 


\subsection{Methods of investigation}

From 10 Jan. 2020 to 10 Mar. 2020, we did the investigation. We sent 140 pieces of electronic questionnaires to the students through WeChat and taken back 135 pieces. And from 10 Apr. 2020 to 16 Apr. 2020, we have done an adding investigation used the online survey tool "questionnaire star ", 27 graduates of Japanese major over 35 years old were the subjects.

\section{Summary of the Investigation}

Fig.1. shows the statistics of respondents in the investigation.

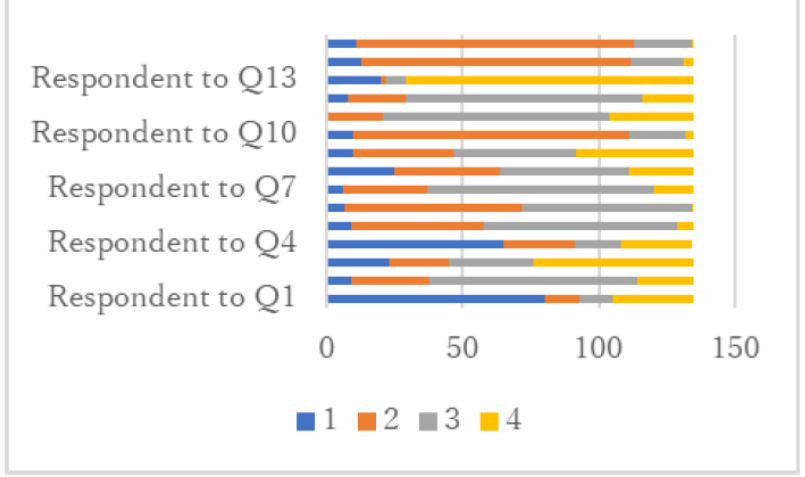

Fig.1. Statistics of the respondents

\subsection{Summary of the motivation for choosing Japanese major}

For Q1: Why did you choose the Japanese Major?

1. I like Japanese electronic media. 2. I like Japan.

3. I want to study in Japan. 4. I want to find a job in Japanese.

$59 \%$ of the respondents focus on Opinion1(Japanese media), $59 \%$ of subjects of the investigation had been influenced by Japanese media.

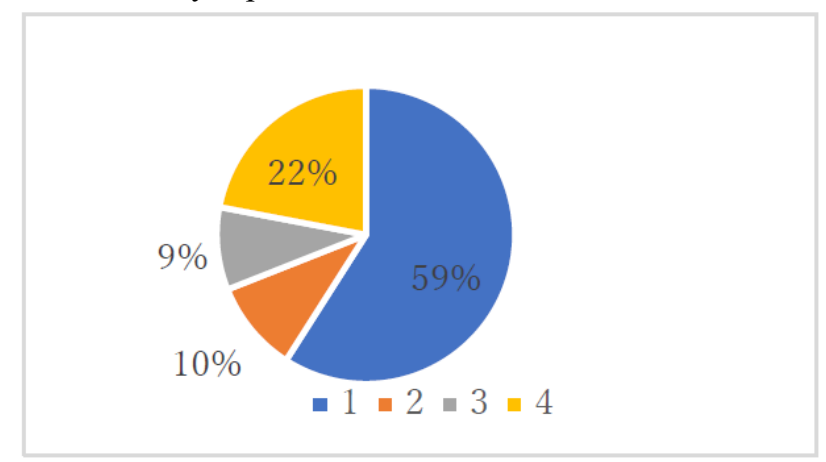

Fig.2. The respondent percentage for Q1

By contrast, $56 \%$ of the subjects(aged 35 52) of the adding investigation indicated the reason that they choose the Japanese Major is for searching for a job.

In history, Dalian was a Japanese colony in the 1930s. To popularize Japanese culture, people passively studied Japanese. At the beginning of the establishment of New China, studying Russian was the mainstream because of friendly relations with Russia, but Dalian has been at the forefront of Japanese language education because of the need to learn from Japan's advanced experience. Especially from the friendly exchange between China and
Japan. In the 1980s and 1990s, Japanese companies began to enter the Chinese market, Japanese companies pay very high wages, many people learn Japanese to enter Japanese companies. Now, the phenomenon of learning Japanese as a major because of liking Japanese media has occurred in reality.

\subsection{Summary on the tendency of the students to choose Japanese media}

Q4: What Japanese programs do you like to watch?

1.Animation 2. Variety Show 3.Funny Show 4.Drama

From the respondents, we can see $46 \%$ of the student choose 1.Animation. Many students choose 2.Variety Show and 4.Drama, but less half of 1.Animation. Students who choose 3.Funny Show was the least, because of the difficulty in understanding. To understand the Funny Show, not only understand the language but also the culture behind the language. For the students without Japanese culture, grasping the laughing point is difficult.

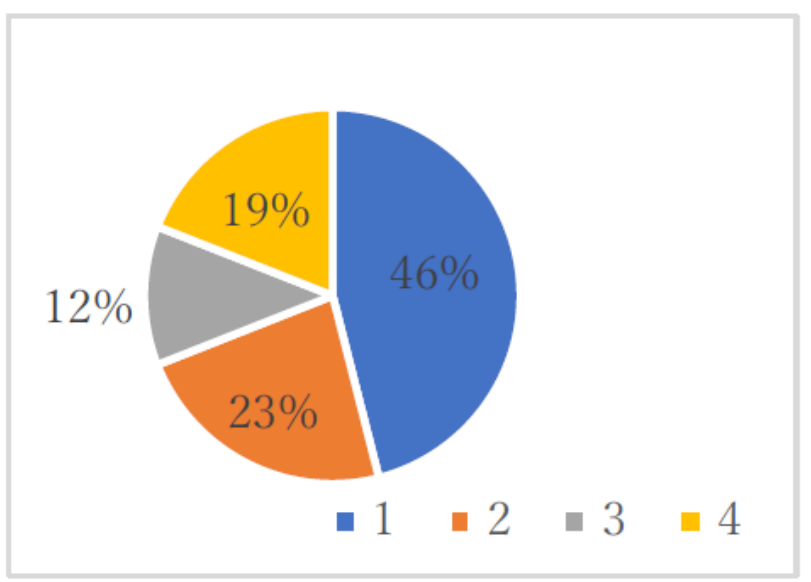

Fig.3. The respondent percentage for Q4

We also asked the students to write reasons for liking Japanese media. For 1.Animation, the main reason is a)the story interesting, meaningful, and charming b)The screen design is great. As the reasons to like 2. Variety Show, there are 32 messages, the main reason is a)the content is interesting and relaxing; b) the content is true it can help to understand Japan; c) it is helpful to train Japanese hearing; d)it is helpful to understand Japanese culture; For 3. Funny Show, the main reason is a)It is funny, very relaxed; b)it is helpful to train Japanese hearing; For 4.Drama, the main reason is a) the content is Philosophical, meaningful; b) it is helpful to understand Japanese culture; c) it is helpful to train Japanese hearing.

\subsection{Summary on the attitudes of the students to the role of Japanese electronic medias}

In Fig.4, we can see the respondent to Q7 (Do you think watching Japanese Media is useful for your learning Japanese?). And we can see, in Grade1 nobody think it is no use, $86 \%$ of the students think it is useful and highest among 4 grades. And we can see Grade3's attitude is the lowest. 


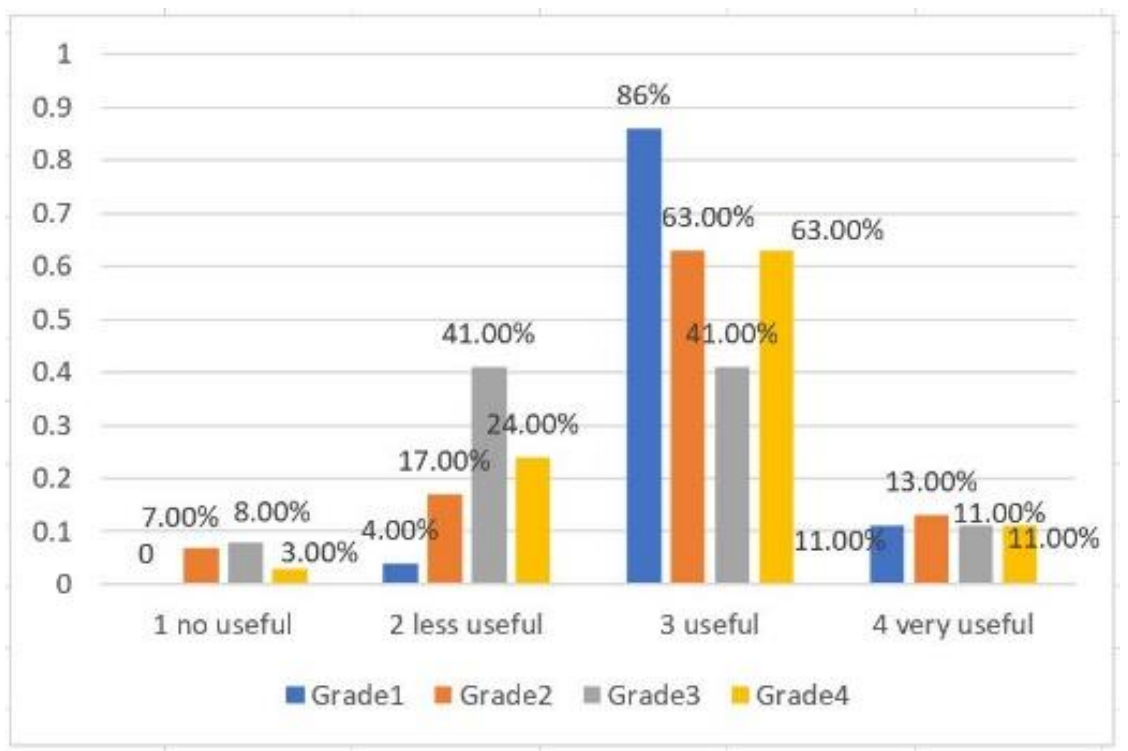

Fig.4. The respondent percentage for Q7

About the detail of the role of Japanese electronic media in learning Japanese, there is no big difference among the four opinions(1. vocabulary 2. pronunciation 3 . Japanese culture 4. Japanese society), but more students think it is helpful to understand Japanese culture and improve pronunciation. It can be said, the biggest problem in learning Japanese in China is no Japanese environment, fewer opportunities to communicate with Japanese, no hearing of native Japanese. By watching Japanese media, you can familiarize yourself with native Japanese, and experience Japanese culture in TV or video stories.

And we see more the thinking of the students. We asked them to write out the role of watching the Japanese media what they usually use. There are three answers: useful for listening exercises (49 persons), useful for word memory ( 25 persons), and useful for conversational exercises (23 persons). We can say While watching the Japanese media if you want to improve your "hearing" "vocabulary" and "pronunciation" you must pay attention to the sound, words, and conversation, but if you want you to understand "Japanese culture or social" you can learn by paying attention to Chinese lines. "Japanese culture "Japanese society" is mainly from the content of Japanese programs, In short, in the students' opinion, watching Japanese media can improve Japanese listening ability, Japanese vocabulary memory, Japanese conversation ability.

But in China, most of the Japanese electronic media that the students can watch are those with Chinese lines, so, it is a problem in Japanese learning.

\section{Discussion the respondents of the top students summary of the Investigation}

From the subjects in the investigation, we selected 59 Students (S1 S59), the top students above 80 points in the final examination of the 2019-2020(2) semester. We used the Correl function to analyze the association between the respondents and their points, summarized in Fig.5.

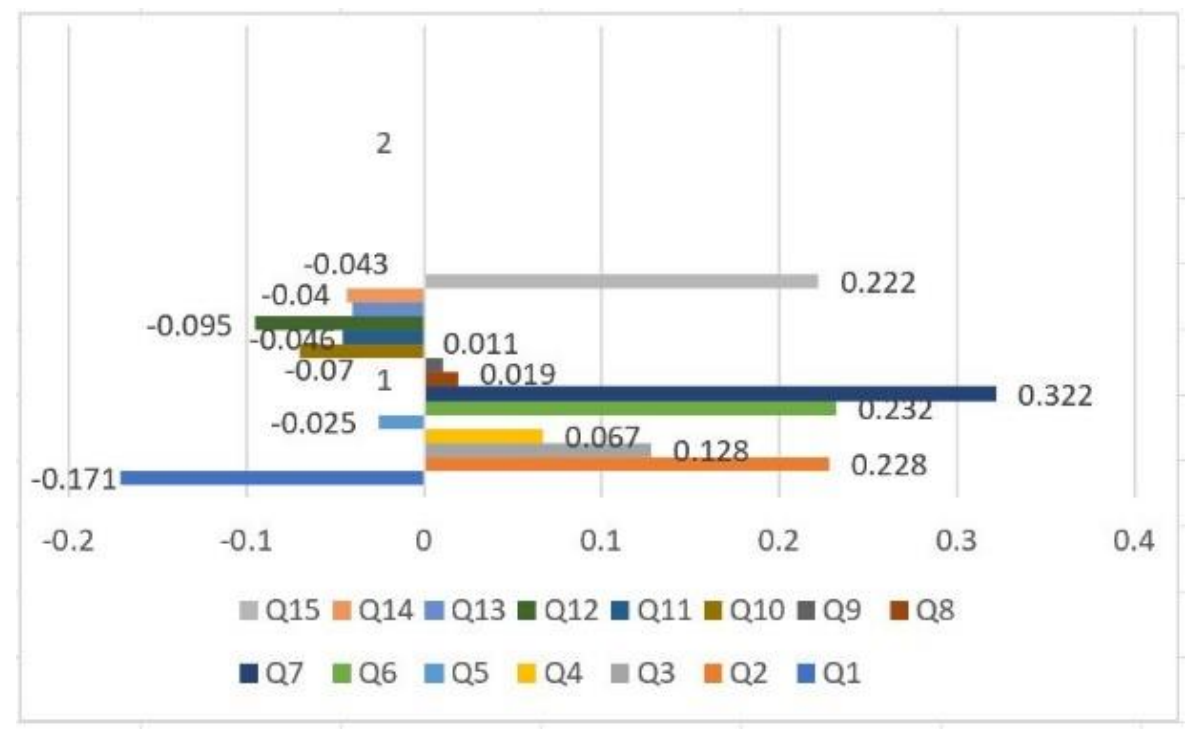

Fig.5 The Correl of the respondents and score 
As can be seen from fig.5, the high point correlates with Q7, Q6, Q2, Q15. Let's see more deeply on the data about Q7, Q6, Q2, Q15.

The Correl function is categorized under Statistical functions. It will calculate the correlation coefficient between two variables. The equation for the correlation coefficient is:

$$
\operatorname{Correl}(X, Y)=\frac{\sum(x-\bar{x})(y-\bar{y})}{\sqrt{\sum(x-\bar{x})^{2} \sum(y-\bar{y})^{2}}}
$$

Where $\bar{x}$ and $\bar{y}$ is the sample means the average of variables? If the Correl function value is close to +1 , it indicates a strong positive correlation, and if the Correl function value is close to -1 , it shows a strong negative correlation.

\subsection{Top students admit the role of watching Japanese Media in Japanese learning}

The Correl function value in Q7 is 0.322 . This is the highest positive correlation with results in this survey. From the details of the respondent, although there are some differences in the scale of recognition, it can be said that almost everyone agrees that watching Japanese media plays a good role in Japanese learning.

\subsection{Top students can`t understand Japanese Media very well}

The Correl function value of Q6 is 0.232 , which can be said to be positively correlated. Though students watch Japanese media, as shown in the investigation result, that even the top students can understand about half and not very well.

\subsection{Top students spent less time watching Japanese Media}

The Correl function value of Q2 is 0.228 , positive correlation, less viewing frequency, will achieve a good score. As shown in the investigation result, the respondent of the top students focuses on "3 occasionally ". Watching Japanese media is an auxiliary means of learning, and spending more time is not good.

\subsection{Top students remember lines for Japanese learning}

The Correl function value of Q15 is 0.222 , which can be said to be positively correlated. As shown in the investigation result, when watching Japanese media, remembering the lines in the media plays a good role in learning Japanese.

\section{Conclusion}

\subsection{Japanese electronic media play an important role in choosing Japanese major}

Among the current Japanese majors, there is a tendency that young fellows choose Japanese majors because they like Japanese electronic media. Japanese animation becomes an important motivation to learn Japanese. This motivation should play a good role in learning Japanese.

\subsection{Different characteristics in different Grades}

About the frequency of watching Japanese electronic media, each grade has its characteristics. The data tell us, the students in Grade2 and Grade3 watch it more frequently. The students in Grade1 watch seldom because of the limitation of Japanese ability. The frequency of the students in Grade4 also tends to calm down.

About the role of watching Japanese electronic media, each grade has its characteristics too. In Grade1, no one thinks that it is "not helpful" to learning Japanese, while there are 7\% in Grade2, 8\% in Grade3, and 3\% in Grade 4. But students with a "very useful" attitude almost have the same proportion of different Grades. On the whole, the higher the class, the weaker the role of Japanese media for Japanese learning. For this point, from the experience be a Japanese teacher and a Japanese learner, watching Japanese media is helpful to hearing and speaking, but it is not helpful for reading and writing. So the students in higher Grades what their main learning task is reading and writing should better not spend too much time watching Japanese electronic media.

\subsection{Choose the better method to use Japanese electronic media}

Concerning the role of watching Japanese electronic media, the date says, if you pay attention to the sound, it is very helpful to the study of hearing, pronunciation, conversation, that is, the study of Japanese sounds. But, if you are for a relax or the entertainment, paying more attention to the storylines, it can not help your hearing or speaking, it is helpful for the study of Japanese culture and society. From the investigation result, it can be seen that most students pay more attention to the storylines. It is necessary to call on students and teachers to pay attention to their methods that they use the Japanese electronic media. You must choose a better method to watch Japanese electronic media for achieving your purpose.

\subsection{Conclusions From the research on the top students}

(1) The top students highly appreciate the help of Japanese electronic media to their Japanese learning. It is recommended to introduce appropriate animation in the Japanese listening class. And we also can introduce Japanese culture through Japanese electronic media.

(2) Students watch Japanese electronic media, even the top students "understand about half" and " understand not well". It shows that studying how to help students to understand Japanese electronic media better is so necessary.

(3) About the frequency of watching Japanese electronic media, the top students' answer focused on "3 occasionally". So, watching Japanese electronic media to 
learning Japanese is just an auxiliary way, or it isn't working well.

(4) Of the 59 top students, 28 persons, 47\%, start watching Japanese media after entering university. It can be said that at the beginning of learning Japanese while holding the intention to learn Japanese, while watching Japanese electronic media, this brings them a good result.

\section{Future topics}

Through this investigation, it is clear that the Japanese electronic media has an important influence on Japanese learning. $59 \%$ of the subjects had chosen the Japanese Major because they like Japanese electronic media. We should convert the students' enthusiasm into the motivation to learning Japanese. The learns had improved their hearing, pronunciation, conversation, and under the Japanese culture and society by watching Japanese electronic media.

However, be a Japanese teacher, from my experience, I think there are still several problems:

(1)Students are very enthusiastic about Japanese electronic media, but this enthusiasm is not be converted into learning power enough;

(2)Most students watch Japanese electronic media for entertainment, with little effect on learning;

(3)The guidance on how to use Japanese media to learn Japanese is very little.

In fact, from my Japanese learning experience, at first, when I watch Japanese electronic media without Japanese subtitles, I couldn't understand it. So I looked for the Japanese electronic media with Japanese subtitles. And then, I found that listening to Japanese lines at the same time reading Japanese subtitles was the best way for my Japanese learning. However, in China at present, the Japanese electronic media that students often watch is those with Chinese subtitles, so it's not good at Japanese learning. Because when you watch Chinese subtitles you understand the story in Chinese, you will forget Japanese learning. Watch the lines, at the same time, listen to the lines, it's very important.

As a better way to learn Japanese by using Japanese electronic media, from this investigation and my personal experience, listening to lines at the same time watching subtitles, and watching the same content repeatedly until understanding, trying to remember lines, and so on, really help Japanese learning.

Through this investigation, it showed that the application of Japanese electronic media in Japanese Learning is not good. The application of Japanese electronic media in Japanese learning will be continued.

\section{Acknowledgments}

Thank the students for their helping in the Questionnaire Survey.

\section{References}

1. S.Tokumaru, Qualitative Research on Self-learner
Who Started Learning Japanese through Watching Japanese Animation, Kaichi International University Bulletin No.18

2. Y.Nishihara,J.Shan,R.Yamanishi,J.Fukumoto,

Recommendation of Spoken Lines of Comic by Evaluating the Degree of Difficulty for Learners of Japanese, The 30th Annual Conference of the Japanese Society for Artificial Intelligence (2016)

3. N.Fukui, S.Kawaguchi, Designing a Japanese Learning Environment for Peer Learning Using the Social Networking Service BEBO, Electronic Journal of Foreign Language Teaching (2015, Vol. 12, No. 1, pp. 115-134)

4. N.Usui, Animation Research in Japanese Education to date and the Future, Japan Research Education Annual Report 21 (2017.3)

5. Y, Miguni, M.Taniguchi, T.Iwashimo, T.Kawasaki, Shiji Zhang, N.Iwamoto, The Actual Situation of Japanese Learners Using Media Outside the Classroom-Questionnaire Survey from Six Countries, Eibilin Language Education Journal 7 (January 2011) 